Scientific Review - Engineering and Environmental Sciences (2021), 30 (4), 537-551

Sci. Rev. Eng. Env. Sci. (2021), 30 (4)

Przegląd Naukowy - Inżynieria i Kształtowanie Środowiska (2021), 30 (4), 537-551

Prz. Nauk. Inż. Kszt. Środ. (2021), 30 (4)

https://srees.sggw.edu.pl

DOI 10.22630/PNIKS.2021.30.4.45

Saja S. ALKHATTAT, Munaf A. Al-RAMAHEE

University of Al-Qadisiyah, College of Engineering

\title{
Shear performance of reinforced self-compacting concrete beams incorporating steel and polypropylene fibers
}

Key words: steel fiber, lightweight concrete, polypropylene fiber, shear strength

\section{Introduction}

Concrete improvement is an important aspect of modern construction development. Self-compacting concrete (SCC) is characterized as concrete that can flow on its weight without any compaction effort and can fill voids in all corners and gaps. The use of superplasticizers, mineral additives, high content of fine materials and mortars, contributes to greater cohesion and fluidity of the paste, on the other hand, concrete absorbs less energy (Rahman, Usman \& Al-Ghalib, 2012). With the use of SCC, fewer construction workers are required during the casting stage, and the noise level created by mechanical vibration equipment is minimized, resulting in reduced sound impacts on the environment (Okamura \& Ozawa, 1996). Improving working con- ditions and the climate and has been created commonly used to create complex-shaped beams or structures with a high density of reinforcement (Barros, Gomes \& Barboza, 2011). However, when a regular weight and high specific gravity aggregate in some cases have a concern regarding the structural weight, the lighter weight aggregates are needed. In this case, the coarse aggregates are partially or completely replaced by lightweight aggregate (Siva Rama Prasad, 2017). Aside from its structural uses, lightweight aggregate concrete (LWAC) primarily increases building thermal conductivity and sound insulation properties (Ahmad, Chen \& Shah, 2019). Artificial LWA, such as sintered fly ash, expanded clay, and expanded shale, are commonly used in the manufacture of LWC as they have a lower density, greater longevity, and higher specific strength. Lightweight self-compacting concrete (LWSCC) is rendered by replacing the usual coarse aggregates in SCC with lighter coarse aggregates which produce a new type of high-performance material that incorporates 
the benefits of both SCC and LWC (Liu, $\mathrm{Wu}$, Yang \& Wei, 2019). The LWSCC is expected to have good workability without segregation and high reliability despite being lighter. The use of aggregates is essential to the development of high-quality LWSCC. Expanded clay (LECA) is a ceramic medium made by rotary kiln expansion and verification of selected clay. Other lightweight aggregates such as expanded shale, pumice, granite, perlite, bottom ash, and others have been used successfully in the manufacture of lightweight concretes (LWCs) (Hwang \& Hung, 2005; Wu, Zhang, Zheng \& Ding, 2009; Alkhattat \& Al-Ramahee, 2021). The incorporating of fibers in concrete can improve both the physical properties of the concrete and the structural performance (Sahmaran, Yurtseven \& Yaman, 2005). Fibers can also help strengthen the bond between lightweight concrete and the reinforcing bar. Hybrid fibers are fibers that are also added to concrete by mixing various kinds of fibers such as polypropylene and steel fibers. The SCC is affected by the type of powder that is added to its mix such as limestone powder and fly ash. Topcu, Bilir and Uygunoğlu (2009) have been studied different dosages of powder and found that when its amount more than: $200 \mathrm{~kg} \cdot \mathrm{m}^{-3}$, the workability was not affected while the compressive strength decreased. The fresh mix properties such as slump flow, L-box, and v-funnel test were improved when the used amount of powder was less than $200 \mathrm{~kg} \cdot \mathrm{m}^{-3}$ (Mazaheripour, Ghanbarpour, Mirmoradi \& Hosseinpour, 2011). The compressive strength increased at the late age by using fly ash while the limestone powder increased the compressive strength at the early and the late ages (Topcu et al., 2009). Ramanathan, Baskar, Muthupriya and Venkatasubramani (2013) examined the effects of various mineral admixtures, such as fly ash, ground granulated blast furnace slag, and silica fume, on the fresh and hardened properties of SCC. These minerals had a passable impact on the fresh properties. With successful execution on the fresh state of SCC, blast furnace slag has higher workability than fly ash and silica fume. When using a 30\% mineral admixture replacement ratio and water/powder ratio of 0.35 to minimize the segregation, the mechanical properties compressive, splitting, and flexural strength was improved significantly. Vijayalakshmi and Ramanagopal (2018) found that the specific weight of LWC was around (16-48\%) less than that of normal-weight concrete with high water absorption and strength ranging from 24 to $60 \mathrm{MPa}$ after 28 days of curing. The density of concrete was also decreased, ranged from 1,290 to $2,044 \mathrm{~kg} \cdot \mathrm{m}^{-3}$. Rashad (2018) found that when LECA was used as a coarse aggregate, the compressive strength decreased by $12.5-38 \%$, the density decreased by $16.36-36.51 \%$, and all other properties, such as chloride attack, shrinkage, and resistance to melting and freezing, decreased by $12.5-38 \%$. The shear behavior of LWC beams was investigated and compared to that of normal concrete beams. It was discovered that the overall maximum shear strength of LWSCC beams was $15.8 \%$ lower than that of normal concrete beams. This reduction in strength was due to the use of LWC (expanded clay). It was also discovered that increasing the main reinforcement increase the shear strength (Garcia, Lannes, Carneiro \& Lara, 2020). Raman- 
janeyulu, Srigiri and Rao (2018) examined the impact of expanded clay on the LWSCC's strength and durability. The results showed that LWSCC had a lower density than standard concrete, ranged from 1,870 to $1,950 \mathrm{~kg} \cdot \mathrm{m}^{-3}$. However, increasing the amount of LECA caused segregation, and increasing the dosage of superplasticizer led to less resistance to the effects of sulfate and acids than natural aggregate self-compacting concrete. The impact of steel fiber on the fresh and hardened properties of LWSCC with $0.5 \%$ steel fiber was investigated, and it was discovered that workability decreased while compressive strength and elasticity modules - improved. The mixes reinforced with steel fiber had greater energy absorption ability and soften performance (Gao, Sun \& Marino, 1997). Gencel, Ozel, Brostow and Martinez-Barrera (2011) examined the effect of the addition of polypropylene to self-compacting concrete and found that when the fiber is distributed evenly, there is no issue with followability. Increasing fiber content contributes to an increase in fracturing, compressive, and Young's modules. Compressive strength is improved when $0.6 \%$ steel fiber and $0.3 \%$ polypropylene were added. As the hybrid content was increased, the tensile and flexural strength increased by around 129 and $206 \%$, respectively with keeping the polypropylene ratio constant at $0.3 \%$ (Ibrahim \& Abbas, 2019). Karimipour, Ghalehnovi, de Brito and Attari (2020) performed a study on polypropylene fiber and its effect on SCC and discovered that the optimal ratio for improving tensile and flexural strength, as well as impact and heat resistance, was $0.3 \%$. However, this resulted in a decrease in compres- sive strength. The lightweight concrete is week in compression and tension, so to enhance the performance of such beam, steel and polypropylene fiber were added in this study. The steel and hybrid (polypropylene with steel) fibers were added as $1 \%$ volumetric a to study their effect on the shear behavior of lightweight self-compacting reinforced beams that made with partial and full replacement of coarse aggregate using LECA.

\section{Experimental program}

In the experimental program, seven simply supported beams with dimensions of $150 \times 250 \times 1,650 \mathrm{~mm}$, as listed in Table 1, were cast to investigate various factors that can influence the structural behavior. In the specimen nomenclature, the two digits that follow the letters SR refer percentage of coarse aggregate replacement by LECA ( 0 for no replacement, 50 for partial replacement, and 100 for full replacement), followed by 00 to refer no fiber added, letters SF which refers to $1 \%$ steel fiber, or letters SP refers to $0.75 \%$ steel and $0.25 \%$ polypropylene fiber (hybrid fiber). The first beam (SR00-00) was used as a control beam for comparison purposes and was fabricated entirely using SCC (no LECA replacement and no fibers). Expanded clay has been employed to make two lightweight reinforced concrete RC beams in place of coarse aggregate. The first lightweight beam (SR50-00) was cast with 50\% coarse aggregate replacement, while the second (SR100-00) was prepared with $100 \%$ replacement. After that, steel fibers and hybrid fibers were added to each form of LWSCC. Based on the findings 
of a previous report (Mazaheripour et al., 2011), the volumetric percentage of used fiber was set at $1 \%$. The steel fiber had a percentage of $0.75 \%$ and the polypropylene fiber had a percentage of $0.25 \%$ in the hybrid fiber, Figure 1 shows the steel and polypropylene fiber. Other materials that used in this research were Portland cement that follows the Iraqi specification the IQS No 5/1984 (Central Organization for Standardization and Quality Control [COSQC], 1984), coarse aggregate with a max size of $10 \mathrm{~mm}$ and, fine aggregate with sulfate content $\left(\mathrm{SO}_{3}\right)$ of 0.34 from Al-Najaf inquire, limestone powder (LP) with a specific gravity of $1.07 \mathrm{~kg} \cdot \mathrm{m}^{-3}$, superplasticizer Sika ViscoCrete ${ }^{\circledR}-5930 \mathrm{~L}$, expanded clay (LECA) with a maximum size of $10 \mathrm{~mm}$ and bulk density of $260 \mathrm{~kg} \cdot \mathrm{m}^{-3}$. The water-cement ratio $(\mathrm{w} / \mathrm{c})$ was 0.35 for all mixes. These mixes were based on the results of Abo Dhaheer, Al-Rubaye, Alyhya, Karihaloo and Kulasegaram studies. The details and mix proportions of all used materials are listed in Table 1.

The properties of fibers used in this experiment are listed in Table 2. All beams were reinforced with $2 \Phi 16$ steel bars as main tensile reinforcement and $2 \Phi 10$ steel bars as compressive reinforcement for practical consideration. To ensure shear failure, shear reinforcement was provided using closed $\Phi 10$ at $250 \mathrm{~mm} \mathrm{c} / \mathrm{c}$. Figure 2 depicts the crosssection and steel reinforcement. Slump flow and L-box tests were performed before beam casting, as shown in

TABLE 1. Mix proportions

\begin{tabular}{|l|c|c|c|c|c|c|}
\hline Specimen mix & $\begin{array}{c}\text { LECA } \\
{[\mathrm{kg}]}\end{array}$ & $\begin{array}{c}\text { Cement } \\
{\left[\mathrm{kg} \cdot \mathrm{m}^{-3}\right]}\end{array}$ & $\begin{array}{c}\text { Sand } \\
{\left[\mathrm{kg} \cdot \mathrm{m}^{-3}\right]}\end{array}$ & $\begin{array}{c}\text { Gravel } \\
{\left[\mathrm{kg} \cdot \mathrm{m}^{-3}\right]}\end{array}$ & $\begin{array}{c}\text { Steel fiber } \\
{[\%]}\end{array}$ & $\begin{array}{c}\text { Polypropylene } \\
{[\%]}\end{array}$ \\
\hline SR00-F0 & 0 & 468 & 754 & 858 & 0 & 0 \\
\hline SR50-00 & 100 & 468 & 754 & 429 & 0 & 0 \\
\hline SR100-00 & 200 & 468 & 754 & 0 & 0 & 0 \\
\hline SR50-SF & 100 & 468 & 754 & 429 & 1 & 0 \\
\hline SR100-SF & 200 & 468 & 754 & 0 & 1 & 0 \\
\hline R50-SP & 100 & 468 & 754 & 429 & 0.75 & 0.25 \\
\hline SR100-SP & 200 & 468 & 754 & 0 & 0.75 & 0.25 \\
\hline
\end{tabular}

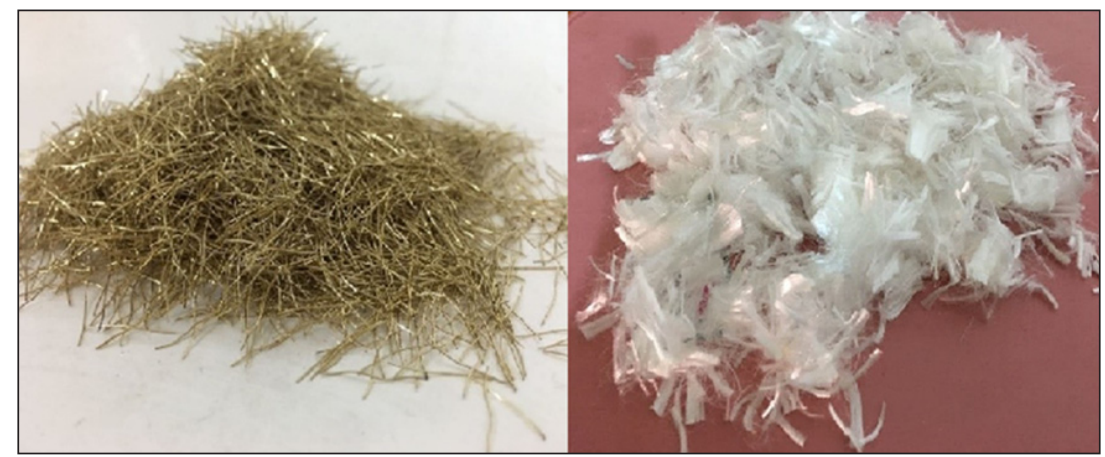

FIGURE 1. Steel and polypropylene fiber 
Figure 3, in accordance with the limitations presented in "The European guidelines for self-compacting concrete" (European Federation of National Associations Representing for Concrete [EFNARC], 2005). The compressive strengths of SCC and LWSCC average 28 -day based on $150 \times 150 \times 150 \mathrm{~mm}$ cubes, splitting tensile strength of a cylinder (dimensions: $20 \mathrm{~mm}$ diameter, $200 \mathrm{~mm}$ height), flexural strength for a $100 \times 100 \times 500 \mathrm{~mm}$ prism, and density for all mixes are described in Table 3 .
Also, fresh properties for all mixes in terms of slump flow and L-box results are listed in Table 4. The average density of partial replacement of aggregate mix (for all types of fibers) was around $1,930 \mathrm{~kg} \cdot \mathrm{m}^{-3}$ while it was around 1,630 $\mathrm{kg} \cdot \mathrm{m}^{-3}$ for full replacement specimens mix. These values agree with the definition of the report ACI 213R-03 (American Concrete Institute [ACI], 2003). The experimental work was performed at the Civil Engineering Structural Lab at the Al-Qadisiyah University.

TABLE 2. Properties of steel and polypropylene fibers

\begin{tabular}{|l|c|c|}
\hline Property & Steel fiber & Polypropylene fibers \\
\hline Diameter $[\mathrm{mm}]$ & $0.2-0.25$ & 0.032 \\
\hline Length $[\mathrm{mm}]$ & $12-14$ & 12 \\
\hline Tensile strength $[\mathrm{MPa}]$ & 2850 & $600-700$ \\
\hline
\end{tabular}

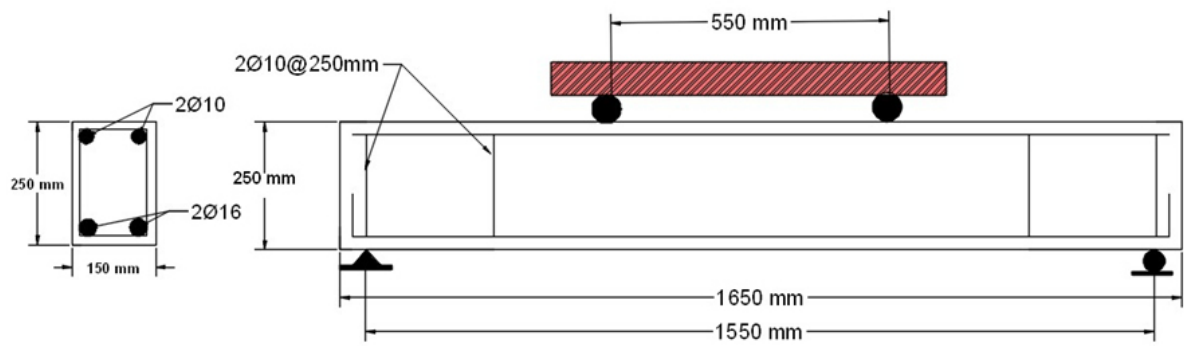

FIGURE 2. Specimens reinforcement details

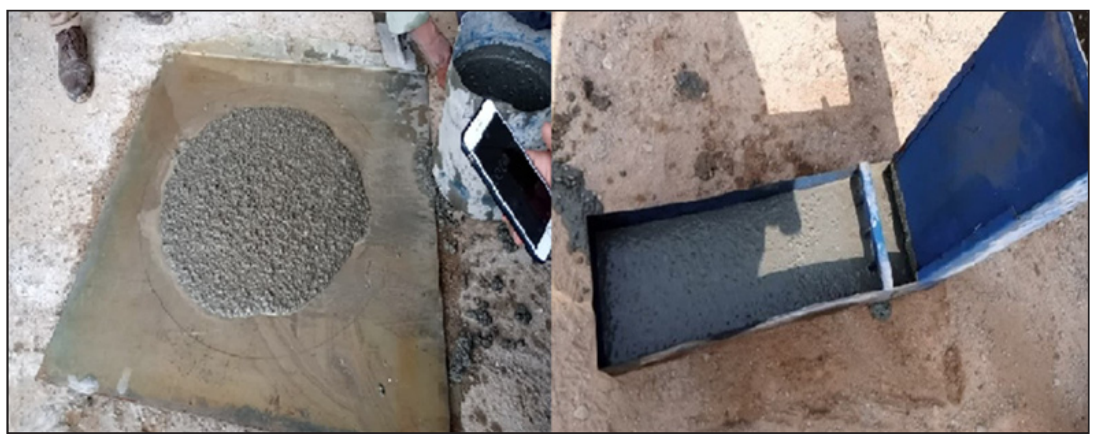

FIGURE 3. Slump flow and L-box test 
TABLE 3. Mechanical properties

\begin{tabular}{|l|c|c|c|c|}
\hline Sample & $\begin{array}{c}\text { Compressive strength } \\
{[\mathrm{MPa}]}\end{array}$ & $\begin{array}{c}\text { Tensile strength } \\
{[\mathrm{MPa}]}\end{array}$ & $\begin{array}{c}\text { Flexure strength } \\
{[\mathrm{MPa}]}\end{array}$ & $\begin{array}{c}\text { Density } \\
{\left[\mathrm{kg} \cdot \mathrm{m}^{-3}\right]}\end{array}$ \\
\hline SR00-00 & 50 & 3.5 & 7.5 & 2220 \\
\hline SR50-00 & 34 & 2.8 & 5.12 & 1915 \\
\hline SR100-00 & 24 & 2.16 & 3.5 & 1620 \\
\hline SR50-SF & 44 & 4.4 & 6.78 & 1950 \\
\hline SR100-SF & 34 & 3.4 & 5.8 & 1750 \\
\hline SR50-SP & 35 & 4.2 & 7 & 1912 \\
\hline SR100-SP & 29 & 3.19 & 5.87 & 1650 \\
\hline
\end{tabular}

TABLE 4. Slump flow and L-box results

\begin{tabular}{|l|c|c|}
\hline Sample & $\begin{array}{c}\text { Slump flow } \\
{[\mathrm{mm}]}\end{array}$ & $\mathrm{BR}=\mathrm{h}_{2} / \mathrm{h}_{1}$ \\
\hline SR00-00 & 740 & 0.857 \\
\hline SR50-00 & 737.5 & 0.88 \\
\hline SR100-00 & 750 & 0.92 \\
\hline SR50-SF & 733 & 0.88 \\
\hline SR100-SF & 730 & 0.85 \\
\hline SR50-SP & 735 & 0.87 \\
\hline SR100-SP & 742 & 0.8 \\
\hline
\end{tabular}

\section{Experimental tests}

A four-point load configuration has been used to test all specimens. The tests were carried out with a $1,000 \mathrm{kN}$ hydraulic jack at a constant rate of $5 \mathrm{kN} \cdot \mathrm{min}^{-1}$ as shown in Figure 4. The central deflection was recorded using an electronic dial gauge attached to the mid-span bottom face. The instrumentation was connected to automated data acquisition devices. Based on visual inspection, cracks were found during the loading stages. If there

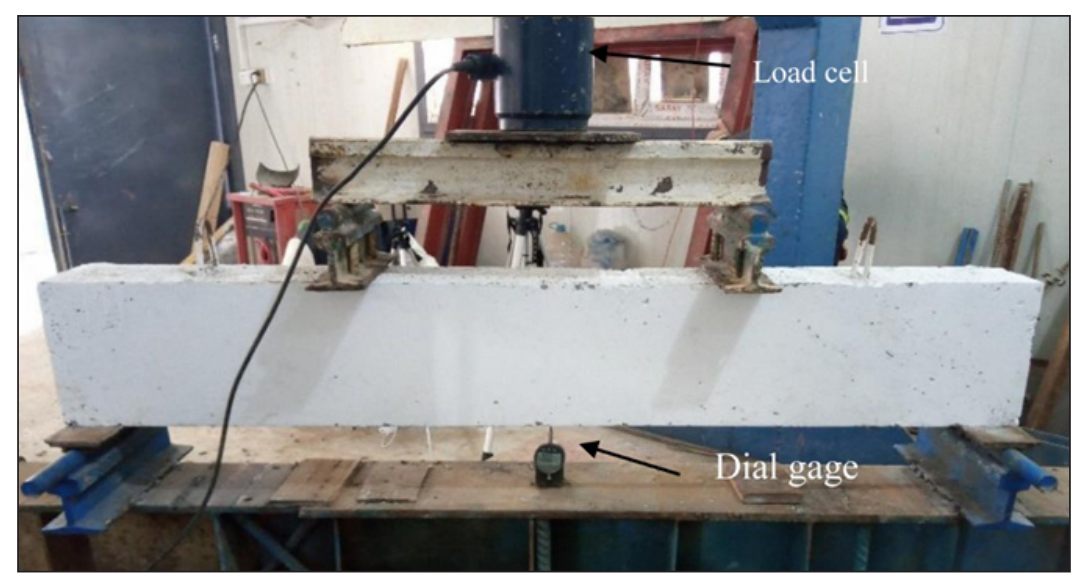

FIGURE 4. Beam with testing machine 
is an excessive deflection or the load has fallen dramatically, beams are deemed to have failed.

\section{Results and discussion}

The control beam (SR00-00) has been made using standard SCC without the addition of any fibers. The first crack was discovered at a load level of $33 \mathrm{kN}$, with a central deflection of $1.05 \mathrm{~mm}$. However, at a load level of $131 \mathrm{kN}$, the first shear crack appeared with $5.44 \mathrm{~mm}$ central deflection. The maximum load applied to this specimen was $215 \mathrm{kN}$, with a central deflection of $12.83 \mathrm{~mm}$.
The load-vertical displacement relation for SR00-00 is shown in Figure 5. Figure 6 shows the crack pattern at failure.

\section{Effect of using lightweight concrete}

Two different percentages of lightweight aggregate LECA (50 and 100\%) replacement have been used. For the (SR50-00) beam with partial replacement (50\% LECA), the first crack appeared at load level of $13 \mathrm{kN}$ with a central deflection of $0.54 \mathrm{~mm}$. The first shear crack appeared at $63 \mathrm{kN}$ with $2.94 \mathrm{~mm}$ central deflection. This beam reached an ultimate load level of $165 \mathrm{kN}$ with a corresponding central deflection of $11 \mathrm{~mm}$.

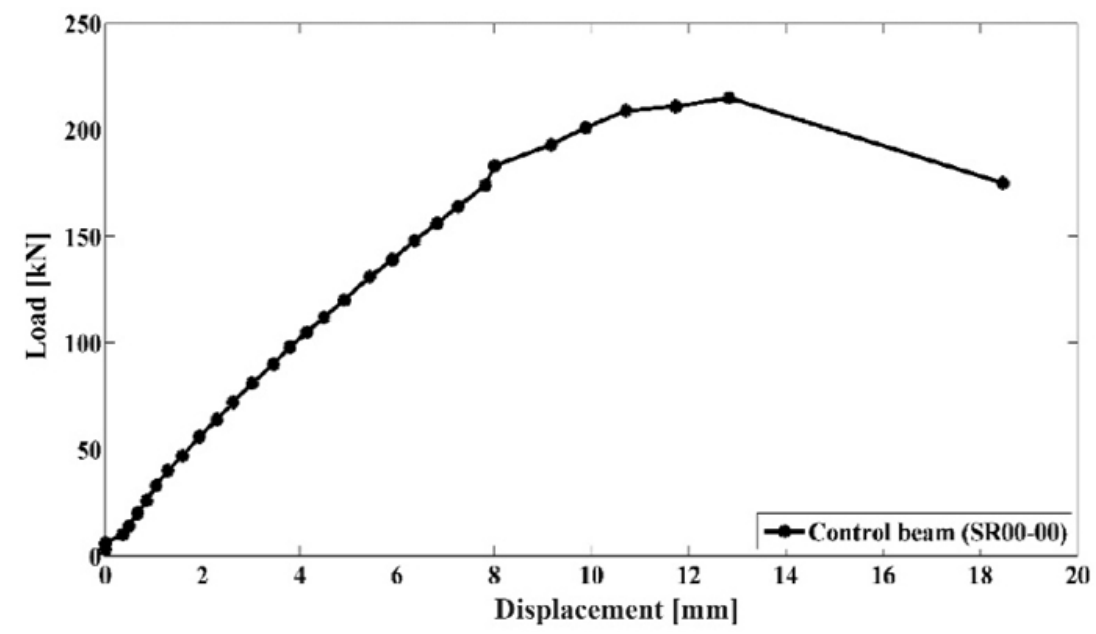

FIGURE 5. Load-displacement relationship for control beam

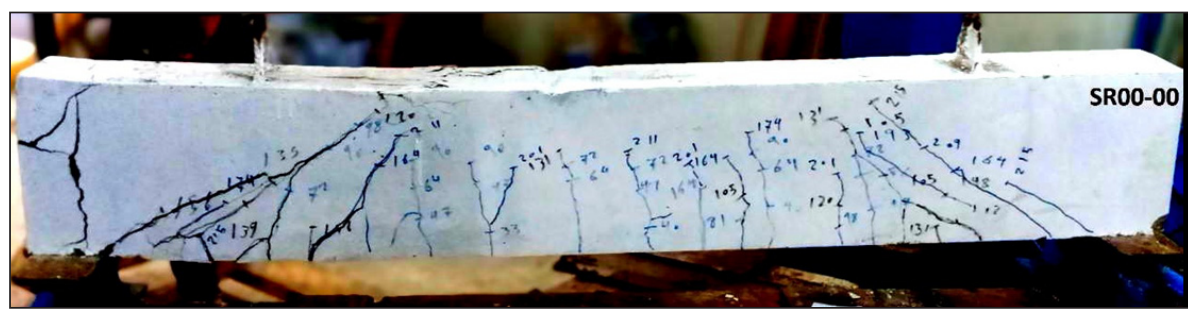

FIGURE 6. Crack pattern in the beam 
Figure 7 shows the crack pattern at the ultimate load level which clearly indicates the shear failure of the beam.

For the (SR100-00) beam that was cast with full coarse aggregate replacement (100\% LECA), the first crack was noticed at a load level of $18 \mathrm{kN}$, with a central deflection of $1.23 \mathrm{~mm}$. However, at a load of $75 \mathrm{kN}$, the shear crack was observed with a central deflection of
$3.79 \mathrm{~mm}$. Moreover, the maximum capacity of this specimen was $175 \mathrm{kN}$, with a corresponding mid-span deflection of $11.2 \mathrm{~mm}$. Figure 8 depicts the crack pattern for this beam with shear failure at the ultimate load.

Figure 9 shows the comparison in load-displacement response for a beam with LECA replacement with the control beam. From this figure, the ultimate loads

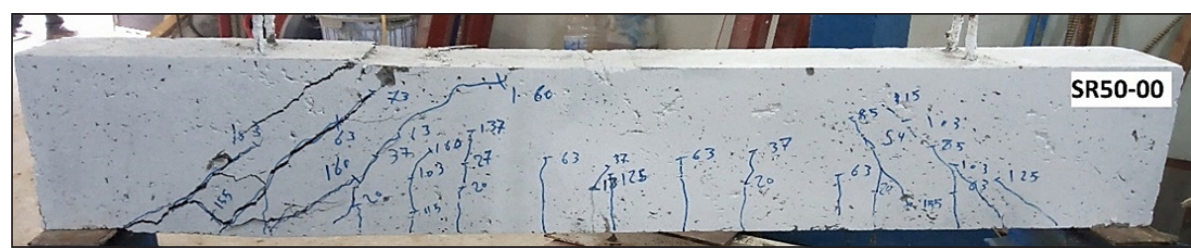

FIGURE 7. Crack pattern for 50\% LECA

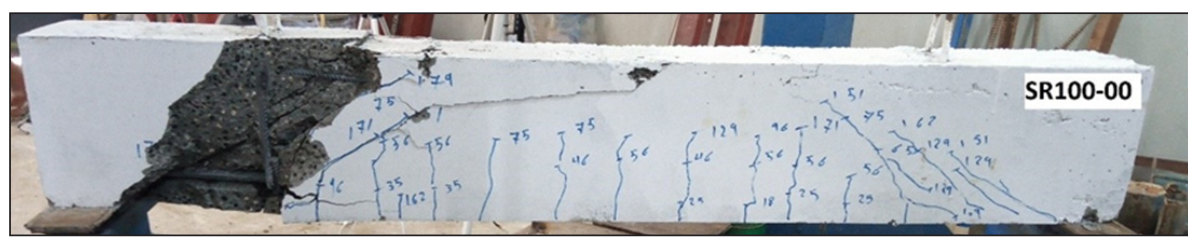

FIGURE 8. Crack pattern for $100 \%$ LECA

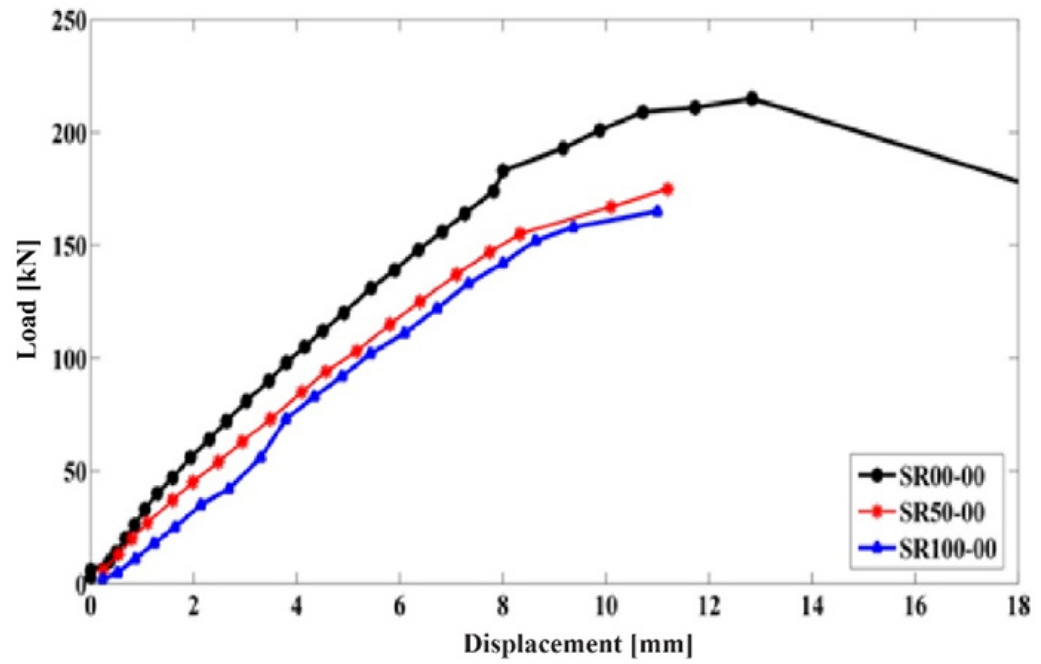

FIGURE 9. Effect of using LECA in SCC beams 
for beam with LECA replacement are reduced by 23 and $30 \%$ for partial and full replacement, respectively when compared with the control beam. It is also worth noting that the SR50-00 when compared to the control beam, there is little difference in its stiffness. While the SR100-00 has a noticeable difference in its stiffness compared to the control beam.

\section{Effect of steel fiber}

The influence of steel fibers on the performance of the LWSCC reinforced beam has been investigated. Steel fiber was used at a volumetric ratio of $1 \%$ for both partial and full LECA substitution. For the SR50-SF beam which rep- resents the SCC beam with partial aggregate replacement and 1\% steel fiber, the ultimate load was $227 \mathrm{kN}$ which represents a $30 \%$ increase compared to the ultimate load for SR50-00 (without steel fiber). The deflection that corresponding to the ultimate load level was $16.17 \mathrm{~mm}$. The first crack for SR50-SF was recorded at a load level of $40 \mathrm{kN}$ with a deflection of $1.64 \mathrm{~mm}$. However, the first shear crack was noticed at a load level of $117 \mathrm{kN}$ with a corresponding deflection of $5.45 \mathrm{~mm}$. The use of steel fiber contributed to enhancing the shear strength of the beam and correspondingly changed the failure mode. The eventual collapse of the beams appeared to be caused by a combination of diagonal

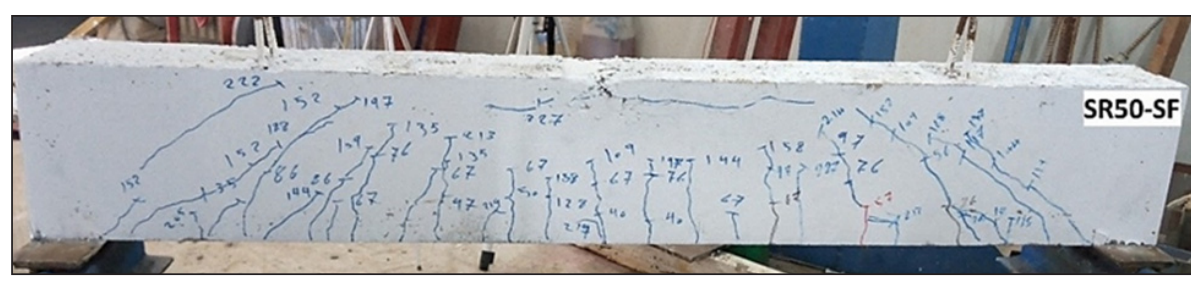

FIGURE 10. Crack pattern for SR50-SF

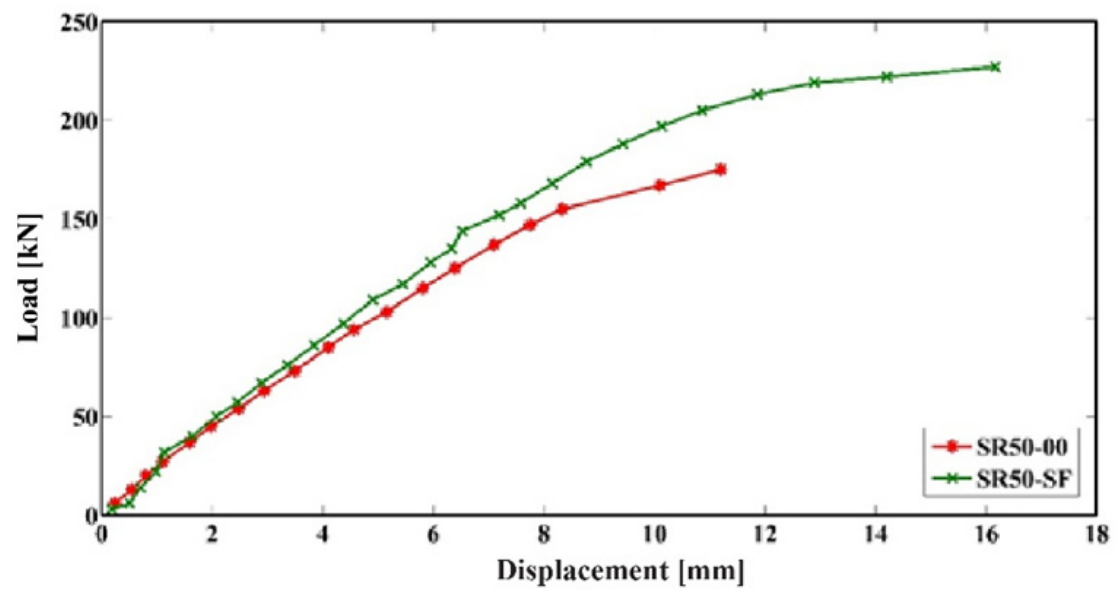

FIGURE 11. Effect of steel fiber on LWSCC beam with partial replacement 
tension failure, flexural cracking at the mid-span, and concrete crushing in the compression area as shown in Figure 10. Figure 11 shows the load-displacement relationship. It was found that the steel fiber made the beam more ductile with reduced the crack width.

The ultimate load level for the beam with full replacement of coarse aggregate and $1 \%$ steel fiber (SR100-SF) was $207 \mathrm{kN}$ which represents a $25 \%$ increase in the load level compared to SR100-00 (without steel fiber). The deflection that corresponding to the ultimate load level was $15.7 \mathrm{~mm}$. The first crack was recorded at a load of $28 \mathrm{kN}$ with $0.85 \mathrm{~mm}$ mid-span deflection. Moreover, the first shear crack was noticed at a load level of $116 \mathrm{kN}$ with $5.11 \mathrm{~mm}$ mid-span deflection. Figures 12 and 13 show the crack pattern and load-displacement relation. Steel fiber usage improves beam stiffness, post-cracking behavior, and load-carrying capacity, as compared to SR100-00. The beams collapsed due to a combination of diagonal tension failure and flexural cracking at the mid-span, as well as concrete crushing in the compression area, which was attributed to the steel fiber's high tensile strength, which increased the beam's shear resistance.

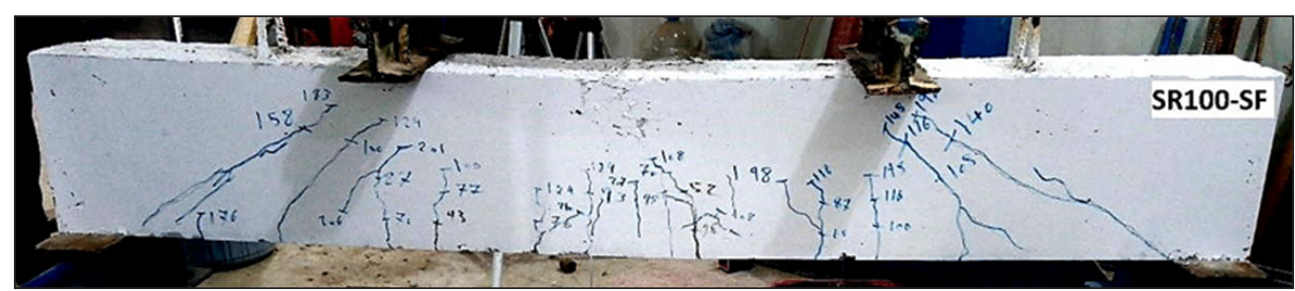

FIGURE 12. Crack pattern of SR100-SF

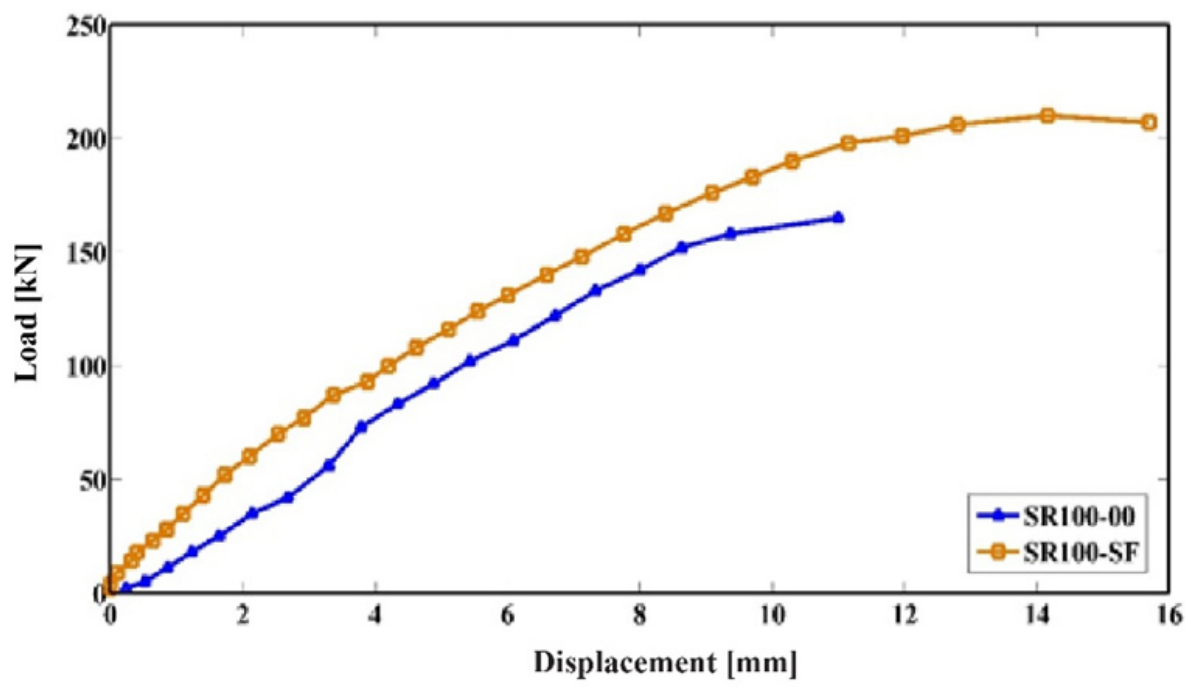

FIGURE 13. Effect of steel fiber on the failure mode for full replacement 


\section{Effect of using polypropylene fibers}

The impact of hybrid fibers on the LWSCC beam's action has been investigated. In this test, the hybrid fibers contain $0.75 \%$ steel fibers and $0.25 \%$ polypropylene fibers as a volumetric ratio. Both partial and full LECA replacement beams incorporating hybrid fibers were investigated. With $12 \mathrm{~mm}$ corresponding central deflection, the SR50-SP beam (50\% replacement contain hybrid fibers) achieved an ultimate load level of $185 \mathrm{kN}$. The first crack was recorded at load level $42 \mathrm{kN}$ with $1.95 \mathrm{~mm}$ central deflection.
At a load level of $108 \mathrm{kN}$, the shear crack was observed with a central deflection of $5.37 \mathrm{~mm}$. Figure 14 shows the crack pattern and failure mode for SR50-SP. In contrast to beams with only steel fibers, it can be seen the shear failure is the dominant failure in lightweight beams with hybrid failure. Figure 15 shows the load-displacement and results in comparison for a beam with partial replacement.

The SR100-SP beam (full LECA replacement and hybrid fibers) has an ultimate strength of $187 \mathrm{kN}$ with a central deflection of $13.48 \mathrm{~mm}$ which represents an increase of about $13 \%$ compared to

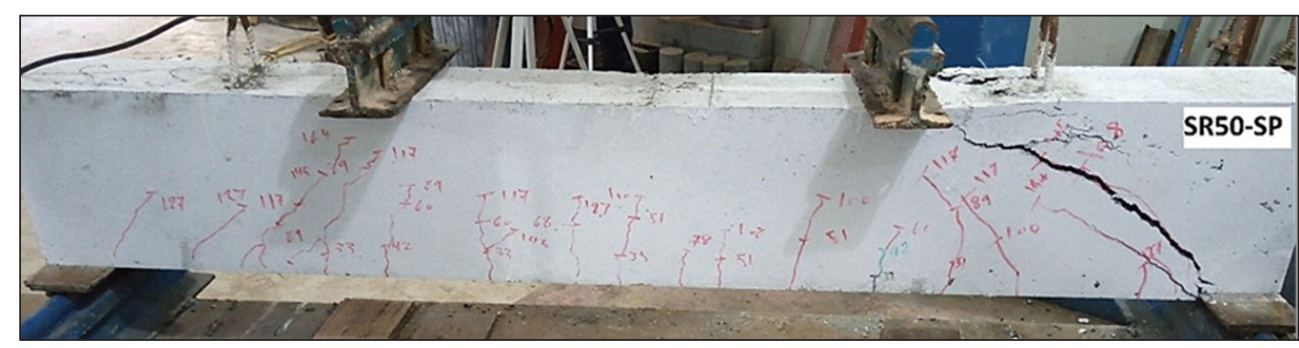

FIGURE 14. Effect of hybrid fiber on the LWSCC beam

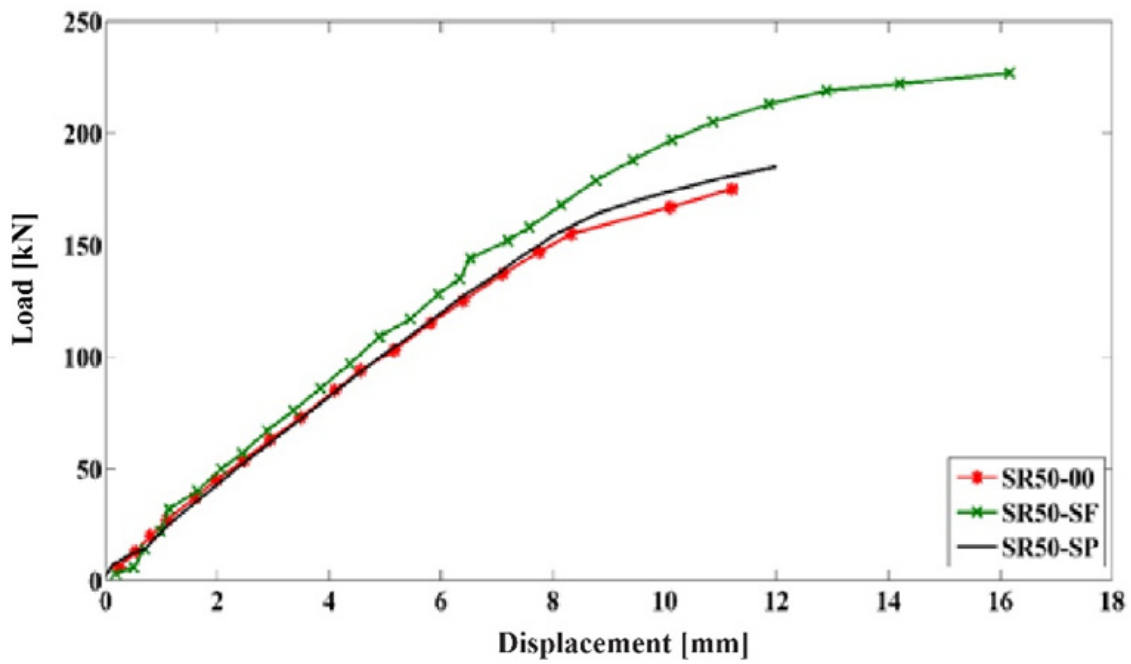

FIGURE 15. Effect of hybrid fiber on the LWSCC beam for 50\% and 100\% replacement 
SR100-00 (beam with full replacement of coarse aggregate and fibers). The first crack was shown at a load level of $30 \mathrm{kN}$ with a central deflection of $1.52 \mathrm{~mm}$. However, the shear crack was observed at a load level of $84 \mathrm{kN}$ with a $4.33 \mathrm{~mm}$ central deflection. Figure 16 shows the crack pattern and failure mode for the SR100-SP beam and Figure 17 shows the load-displacement relationship and the effect of using hybrid (polypropylene and steel) fiber with LWSCC. Similar to beams with partial and hybrid fibers, there was a significant change in the ultimate load with an improvement in the crack pattern, and beam stiffness, and tensile and shear strength of the beam compared to the beam with full replacement and without any type of fibers.

\section{Conclusions}

The performance of lightweight self-compacting concrete (LWSCC) employing two types of fibers was investigated

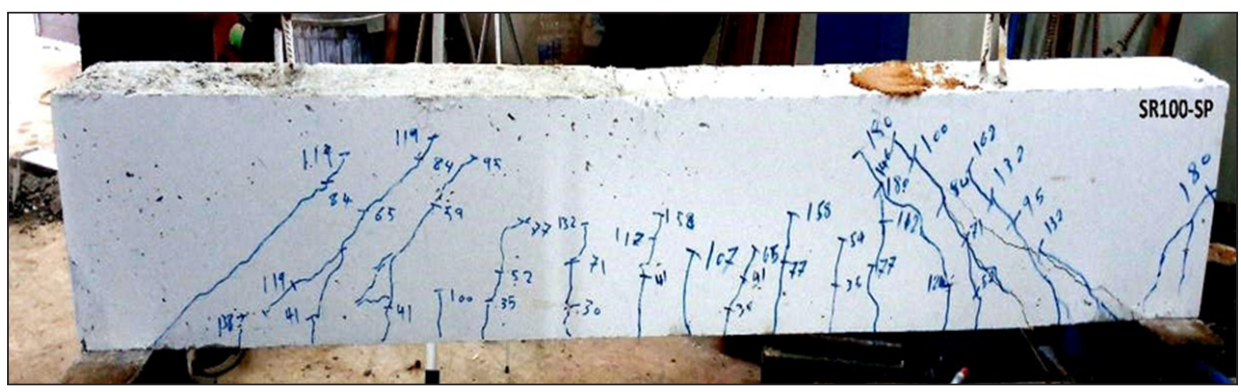

FIGURE 16. Effect of using polypropylene and steel fiber on LWSCC beam

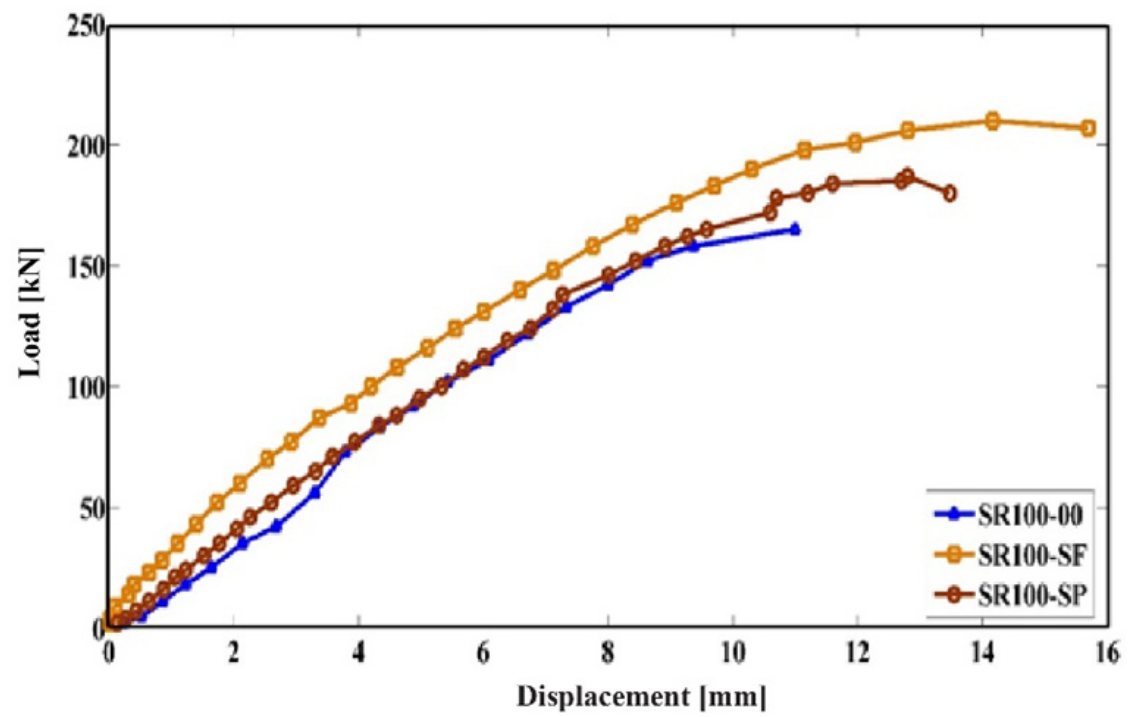

FIGURE 17. Effect of steel and hybrid fiber with 100\% LECA 
in this research. The experimental results of seven beams were discussed in terms of the crack patterns, ultimate load, and deflection and compared with each other. The following are the study's main points and conclusions:

1. When using light weight aggregate in the concrete mix as a partial or full replacement with coarse aggregate led to decreases the density of the structure about $13 \%$ for a partial replacement and about $27 \%$ for full replacement and that make it a lightweight concrete according to the specification of the report ACI 213R-03 definition (ACI, 2003).

2. Lightweight concrete has a greater capacity to bend than conventional concrete, but it also has a greater tendency to segregate. All of the cracking patterns that appeared were identical. For the control beam with a thinner fracture, the crack displayed dispersion followed a similar pattern. Finally, using pre-wetted aggregate had no effect on the self-compatibility or stability of the mixtures.

3. The steel fiber used as $1 \%$ volumetric ratio led to an increase in the compressive, tensile, and flexural strength about 29,43 , and $32 \%$, respectively for partial replacement (50\% LECA), and 41,57 , and $65 \%$, respectively for full replacement (100\% LECA).

4. Using steel fiber led to an increase in the shear strength of LWSCC beam and changing the failure mode from shear to flexure due to the high tensile strength of the steel fiber combined with stirrups, with additional fractures spread over the length of the beam steel fiber increased the stiffness of the beam, improving its ultimate load and beam behavior.

5. The use of hybrid fiber (steel and polypropylene) enhanced the tensile strength by 50 and $48 \%$ for the partial and full coarse aggregate replacement, respectively. Also, it increased the flexural strength by about 37 and $68 \%$ for the partial and full coarse aggregate replacement, respectively compared to lightweight beams without fibers.

6. Beams with fibers have well stiffened, less crack width, and improved load mid-span deflection, increasing shear capacity. Hybrid beams demonstrated a ductile post-cracking behavior since beams without fiber showed considerable deformation before the collapse.

\section{References}

Abo Dhaheer, M.S., Al-Rubaye, M.M., Alyhya, W.S., Karihaloo, B.L. \& Kulasegaram, S. (2016). Proportioning of self-compacting concrete mixes based on target plastic viscosity and compressive strength: Part II - experimental validation. Journal of Sustainable Cement-Based Materials, 5(4), 217-232.

Ahmad, M.R., Chen, B. \& Shah, S.F.A. (2019). Investigate the influence of expanded clay aggregate and silica fume on the properties of lightweight concrete. Construction and Building Materials, 220, 253-266.

Alkhattat, S.S. \& Al-Ramahee, M.A. (2021). Flexural strength of fibrous light-weight self-compacted concrete beams. Journal of Physics: Conference Series, 1973(1), 012221. https://doi.org/10.1088/1742-6596/ 1973/1/012221

American Concrete Institute [ACI] (2003). Guide for structural lightweight aggregate concrete. 
Specification, production and use. ACI Committee 213 report (ACI 213R-03). Farmington Hills: American Concrete Institute.

Barros, A.R., Gomes, P.C.C. \& Barboza, A.S.R. (2011). Steel fibers reinforced self-compacting concrete: behavior to bending. Revista IBRACON de Estruturas e Materiais, 4, 49$-78$.

Central Organization for Standardization and Quality Control [COSQC] (1984). Portland cement (IQS No 5/1984). Baghdad: Central Organization for Standardization and Quality Control.

European Federation of National Associations Representing for Concrete [EFNARC] (2005). The European guidelines for self-compacting concrete. Surrey: European Federation of National Associations Representing for Concrete.

Gao, J., Sun, W. \& Morino, K. (1997). Mechanical properties of steel fiber-reinforced, high-strength, lightweight concrete. Cement and Concrete Composites, 19(4), 307-313.

Garcia, S.L.G., Lannes, C.V., Carneiro, L.A.V. \& Lara, R.C. (2020). Shear behavior of lightweight self-consolidating reinforced concrete beams without transverse reinforcement. Latin American Journal of Solids and Structures, 17(4), 1-13.

Gencel, O., Ozel, C., Brostow, W. \& Martinez-Barrera, G. (2011). Mechanical properties of self-compacting concrete reinforced with polypropylene fibres. Materials Research Innovations, 15(3), 216-225.

Hwang, C.L. \& Hung, M.F. (2005). Durability design and performance of self-consolidating lightweight concrete. Construction and Building Materials, 19(8), 619-626.

Ibrahim, H.A. \& Abbas, B.J. (2019). Influence of hybrid fibers on the fresh and hardened properties of structural light weight self-compacting concrete. IOP Conference Series: Materials Science and Engineering, 518(2), 022022. https://doi.org/10.1088/1757899X/518/2/022022

Karimipour, A., Ghalehnovi, M., Brito, J. de \& Attari, M. (2020). The effect of polypropylene fibres on the compressive strength, impact and heat resistance of self-compacting concrete. Structures, 25, 72-87.
Liu, X., Wu, T., Yang, X. \& Wei, H. (2019). Properties of self-compacting lightweight concrete reinforced with steel and polypropylene fibers. Construction and Building Materials, 226, 388-398.

Mazaheripour, H., Ghanbarpour, S., Mirmoradi, S.H. \& Hosseinpour, I. (2011). The effect of polypropylene fibers on the properties of fresh and hardened lightweight self-compacting concrete. Construction and Building Materials, 25(1), 351-358.

Okamura, H. \& Ozawa, K. (1996). Self-compactable high-performance concrete in Japan. Special Publication, 159, 31-44.

Rahman, M.M., Usman, M. \& Al-Ghalib, A.A. (2012). Fundamental properties of rubber modified self-compacting concrete (RMSCC). Construction and Building Materials, 36, 630-637.

Ramanathan, P., Baskar, I., Muthupriya, P. \& Venkatasubramani, R. (2013). Performance of self-compacting concrete containing different mineral admixtures. KSCE Journal of Civil Engineering, 17(2), 465-472.

Ramanjaneyulu, N., Srigiri, K. \& Rao, M.S. (2018). Strength and durability studies on light weight self-compacting concrete with LECA as partial replacement of coarse aggregate. CVR Journal of Science and Technology, 15, 1-9.

Rashad, A.M. (2018). Lightweight expanded clay aggregate as a building material - an overview. Construction and Building Materials, 170, 757-775.

Sahmaran, M., Yurtseven, A. \& Yaman, I.O. (2005). Workability of hybrid fiber reinforced self-compacting concrete. Building and Environment, 40(12), 1672-1677.

Siva Rama Prasad, C.V. (2017). Light Weight Concrete using Fly Ash Aggregate. International Journal of Innovative Technologies, 5(3), 460-463.

Topcu, I.B., Bilir, T. \& Uygunoğlu, T. (2009). Effect of waste marble dust content as filler on properties of self-compacting concrete. Construction and Building Materials, 23(5), 1947-1953.

Vijayalakshmi, R. \& Ramanagopal, S. (2018). Structural concrete using expanded clay aggregate: a review. Indian Journal of Science and Technology, 11(16), 1-12. 
Wu, Z., Zhang, Y., Zheng, J. \& Ding, Y. (2009). An experimental study on the workability of self-compacting lightweight concrete. Construction and Building Materials, 23(5), 2087-2092.

\section{Summary}

Shear performance of reinforced self-compacting concrete beams incorporating steel and polypropylene fibers. The impact of steel and polypropylene fibers on the performance of lightweight self-compacting concrete (LWSCC) beams was investigated in this study. Seven beams with various parameters were cast and tested. Partial $(50 \%)$ and full $(100 \%)$ replacement of coarse aggregate with lightweight aggregate expanded clay (LECA) were considered. In addition, a $1 \%$ volumetric ratio of steel or hybrid (steel and polypropylene) fiber was added to LWSCC beams to study their effect on the shear performance. The LWSCC beams had a decrease in ultimate load and stiffness of 23 and $30 \%$ for partial and full replacement, respectively when compared to normal weight beam. The addition of steel fiber improved the efficiency of LWSCC beams in terms of crack formation, failure mode, crack width, and ultimate load, as well as changed the failure mode from shear to flexure. The ultimate load for hybrid LWSCC was increased by around $6 \%$ for a partial replacement and 13\% for full replacement as compared to beams without fibers. However, hybrid beams had a larger bearing capacity, little more cracks with smaller size, and ductile failure.

\section{Authors' address:}

Munaf A. Al-Ramahee - corresponding author (https://orcid.org/0000-0002-1922-9871)

(Web of Science ResearcherID W-7313-2018)

University of Al-Qadisiyah

College of Engineering

e-mail: Munaf.alramahee@qu.edu.iq 